\title{
ERGONOMIC INTERVENTION TO REDUCE LOW BACK PAIN AND FATIGUE AMONG NURSES AT PROF DR. WZ YOHANES HOSPITAL, KUPANG, EAST NUSA TENGGARA
}

\author{
Elizabeth Bebhe Sawo, Jacob M Ratu, Anderias Umbu Roga \\ Masters Program in Public Health, Universitas Nusa Cendana
}

\begin{abstract}
Background: Low back pain (LBP) is a common cause of morbidity in health care workers. Low back pain will impose occupational and problem in personal life and also problem in health care system. Nurses are among the occupational groups that are vulnerable to LBP. Low back pain can occur from manual lifting (patients in particular). This study aimed to investigate ergonomic intervention to reduce of LBP and fatigue among nurses at Prof Dr. WZ Yohanes Hospital, Kupang.

Subjects and Method: This was a quasi-experiment with one group pre test post test conducted at Prof Dr. WZ Yohanes Hospital, Kupang, East Nusa Tenggara. Total of 20 nurses with LBP were selected randomly for this study. The dependent variables were LBP and fatigue. The independent variable was stretching intervention conducted for 30 to 45 minutes by simple stretching. Pain level was measured by Oswestry instrument. The data was analyzed by paired t-test.

Results: Level of LBP after stretching (Mean=9.45; SD=3.76) was lower than before (Mean=11.77; $\mathrm{SD}=3.95$ ) or it decreased by $19.74 \%$ and it was statistically significant $(\mathrm{p}<0.001)$. Fatigue score after stretching (Mean $=373.72 ; \mathrm{SD}=39.54)$ was lower than before (Mean $=421.52 ; \mathrm{SD}=50.46)$ or it decreased by $11.33 \%$ and it was statistically significant $(\mathrm{p}<0.001)$.

Conclusion: Strecthing intervention is effective for reducing LBP and fatigue among nurses.

Keywords: low back pain, fatigue, stretching, nurses.

\section{Corespondence:}

Elizabeth Bebhe Sawo. Masters Program in Public Health, Universitas Nusa Cendana, Kupang 85111, East Nusa Tenggara, Indonesia. Email: bfelisio@yahoo.com. Mobile: 081339231014 .
\end{abstract}

